Cancer Causes Control. 2015 May ; 26(5): 775-784. doi:10.1007/s10552-015-0537-0.

\title{
Use of the Persuasive Health Message framework in the development of a community-based mammography promotion campaign
}

\author{
Ingrid J. Hall and \\ Division of Cancer Prevention and Control, Centers for Disease Control and Prevention, Atlanta, \\ GA 30341, USA \\ Ashani Johnson-Turbes \\ ICF International, Atlanta, GA, USA \\ Ingrid J. Hall: ihall@cdc.gov
}

\section{Abstract}

Purpose-We describe how the Persuasive Health Message (PHM) framework was used to guide the formative evaluation informing development of messages and materials used in a community-based multi-media campaign intended to motivate low-income African American women to obtain low- or no-cost mammograms through the CDC's National Breast and Cervical Cancer Early Detection Program.

Methods-Seventy-eight African American women were recruited for eight focus groups that discussed breast cancer screening. The moderator guide was developed in accordance with the PHM framework and solicited information on perceived threat and efficacy, cues, salient beliefs and referents, and barriers to self-efficacy.

Results-We created persuasive messages to emphasize that African American women are susceptible to the threat of breast cancer, but that their personal action in obtaining regular mammograms may lead to early detection, subsequent treatment, and reduced cancer mortality. The messages addressed concerns of self-efficacy by emphasizing that uninsured women can also obtain high-quality low- or no-cost mammograms. In an attempt to combat the sentiment that breast cancer is a death sentence, the messages indicated that breast cancer can be successfully treated, especially when detected early.

Conclusions-The PHM framework consists of three steps: (1) determine information about threat and efficacy; (2) develop an audience profile; and (3) construct a persuasive message. It offered our team easy-to-follow, flexible steps to create a persuasive and effective campaign promoting awareness and use of mammogram screening among low-income African American women.

Correspondence to: Ingrid J. Hall, i hall@cdc. gov.

The findings and conclusions in this report are those of the author(s) and do not necessarily represent the official position of the Centers for Disease Control and Prevention. 


\section{Keywords}

Persuasive Health Message framework; Campaign development; PHM

\section{Introduction}

Health promotion efforts have historically used theory, models, and/or frameworks sporadically and inconsistently [1]; thus, a natural question is why use a theory, framework, or model to guide research? Research indicates that there is great value in using theory or frameworks to guide the development of health communication messages and interventions/ campaigns. First, theories or models can inform the groundwork for health promotion efforts, helping us understand the factors influencing behaviors [2]. Arguably, if we understand those factors, we will be in a better position to identify what strategies and methods to use to help achieve health communication goals [3]. Theories are "useful in planning, implementing, and evaluating interventions" [4] and are particularly valued in health promotion because they can explain influences on health as well as suggest ways where audience change can be achieved $[2,5]$.

The persuasive health message (PHM) framework outlines how to develop effective and persuasive campaigns by combining, into a single framework, parts of successful theories that attempt to explain human behavior. The PHM framework varies from a traditional theory in that it does not explain human behavior; instead, it outlines what should be done to develop an effective and persuasive campaign. The PHM framework combines elements from three prominent persuasion theories-Theory of Reasoned Action [6], Elaboration Likelihood Model [7], and Protection Motivation Theory [8]—-to offer an integrated approach to generating culturally, demographically, and geographically appropriate messages and campaigns. In addition, the PHM framework provides a step-by-step approach outlining how to develop effective and persuasive health messages and communication campaigns [9].

The PHM framework has been used to guide the development of a number of health promotion efforts ranging from preventing tractor-related injuries and deaths in rural populations [10] to developing notification messages at an industrial plant [11]. An extension of the PHM, the Extended Parallel Process Model, has been used to develop a number of messages primarily based on fear appeals $[12,13]$, but has been shown recently to have utility to other types of appeals [14]. The PHM facilitates creation of messages that tap into or create a perceived sense of threat in target audience members while increasing their perceived ability to take action to protect themselves against the threat.

The PHM framework was used as the theoretical backdrop guiding the formative evaluation, typically any evaluation conducted before or during intervention development to improve design and performance, conceived to develop the CDC's award-winning African American Women's Mass Media (AAMM) pilot campaign, a promotional health communication campaign. In this instance, we describe how major components of the AAMM pilot campaign were developed. Since we were interested in how to put together an effective campaign rather than explain behavioral responses, we chose the PHM to guide campaign 
development. This campaign was shown to contribute to an increase in breast cancer screening awareness [15] and, as reported in this monograph, utilization of mammography among low-income, uninsured African American women through the National Breast and Cervical Cancer Early Detection Program (NBCCEDP) in Savannah and Macon, Georgia (GA) [16]. In brief, the PHM framework indicates that two types of factors, constant and transient, must be addressed when designing an effective persuasive health message. The content and features of a persuasive message are structured by the constant factors which refer to structural elements of a message that must always be addressed: threat, efficacy, cues, and audience profile. For example, a persuasive health message must contain a threat and efficacy message, as well as cues such as the channel or outlet used to disseminate the message, and target a specific audience (e.g., low-income African American women). The transient factors of a persuasive message are the parts that change on the basis of different populations, health issues, and message goals. These are the changeable elements of a message/campaign and include a group's salient beliefs, referents, culture, and environment $[9,11]$.

The formative evaluation involved conduct of focus groups to understand what factors influence NBCCEDP-eligible African American women to use local NBCCEDP breast cancer screening services and to determine viable ways to disseminate information to this audience. Findings from the formative evaluation as well as message and materials testing (of audio and print materials) informed the development of a culturally appropriate promotional health communication campaign to reach and increase awareness of breast cancer, availability of NBCCEDP mammography services, and utilization of the NBCCEDP breast cancer screening services for eligible African American women in GA.

The PHM framework consists of three steps: (1) determine information about threat and efficacy; (2) develop an audience profile; and (3) construct a persuasive message [9, 17]. This paper describes how we used the PHM framework process and followed these steps to guide the formative evaluation informing development of the AAMM campaign, messages, and materials to motivate low-income African American women to obtain low- or no-cost mammograms through the CDC's NBCCEDP. The methods and findings of the formative work underlying development of campaign materials have been previously published along with details of feedback received, refinements made, and final materials [18] and documentation of campaign reach [15].

\section{Methods}

\section{Sample and setting}

African American women $(n=78)$ were recruited for 8 focus groups in Savannah and Macon, GA, in 2004. The study sites were selected on the basis of three selection criteria, including (1) similar percent of African Americans in the population, (2) comparable radio market share, and (3) non-overlapping, geographically distinct radio markets. The focus groups were segmented by women's age and screening status. Segmentation by age [40-49 years $(n=38)$ and 50-64 years $(n=40)$ ] was done to encourage discussion and accommodate the different ways younger and older women may view cancer, think about their bodies, and cope with sensitive health topics. The groups were further divided by 
screening status to include women who had received a mammogram in the past 24 months (screened, $n=38$ ) and women who had not received a mammogram in the past 3 years (unscreened, $n=40$ ).

To be eligible for the focus groups, the participants needed to be female, African American, aged 40-64 years, NBCCEDP-eligible, and residing in previously identified zip codes in Macon or Savannah. NBCCEDP-eligible was defined as uninsured or underinsured women with family incomes of $\_50 \%$ of the Federal Poverty Level ("National Breast and Cervical Cancer Early Detection Program (NBCCEDP): Program Eligibility,” 2011). Women with a personal history of any cancer were excluded, as were women who had a relative participating in the groups.

\section{Focus group recruitment}

To ensure participation of 6-10 women per group, at least 15 eligible participants were recruited to attend each focus group session. Recruitment flyers were strategically posted in various locations where the target population frequented, including local apartment complexes, beauty salons, community centers, grocery stores, and Laundromats. The flyers instructed women interested in participating in the focus groups to call a toll-free number to learn more about the groups and be screened for eligibility. Recruiting for focus groups via use of printed flyers was insufficient and did not yield enough potential focus group participants; therefore, we modified our recruitment strategy to use advertisements on local Black radio stations to recruit focus group participants. The use of radio ads proved very successful, and women who responded were informed that the focus groups would be about $2 \mathrm{~h}$ in length and that participants would receive a meal and $\$ 65$ as compensation for their time. Eligible and willing participants were then scheduled for a focus group session.

\section{Conduct of focus groups}

Before each focus group, participants completed an anonymous pre-discussion information sheet (PDIS) that collected information on demographics (e.g., age, race/ethnicity, education, and employment) and participant's use of radio, television, and selected print media. The 15-min paper survey was administered in a group setting and, in addition to the above topics, asked participants if they thought breast cancer was serious, if they were likely to get breast cancer, and if screening would keep them from dying of breast cancer [18]. All focus groups were $90 \mathrm{~min}$ in length and were facilitated by an African American female moderator with extensive experience in conducting focus groups on sensitive health topics. A trained observer took field notes, notes recorded by researchers during observation of the focus groups, on the intensity of comments (responses), facial expressions, and other facets of interpersonal communication (reactions). These notes allowed us to capture the verbal discussion as well as nonverbal cues (e.g., facial expressions) not included in any focus group transcriptions; the notes helped us assess whether nonverbal agreement/disagreement with the verbal discussion was shared widely in the focus group. In addition, the focus groups were audio-recorded and transcribed to facilitate analysis. Informed consent was obtained from all participants before group discussions began. Human subjects approval was obtained from the Institutional Review Boards of CDC, ICF Macro, and the Georgia 
Department of Human Resources. Data collection was also approved by the Office of Management and Budget (OMB NO.: 0920-0652).

A second round of 8 focus groups $(n=66)$ was convened in 2007 to test draft materials developed through the process outlined in this manuscript. Participants were recruited, segmented, and assessed as described above. Groups were convened and facilitated as above. The discussions were not transcribed; however, all focus groups were audiotaped to support the thematic analysis, and field notes were recorded by members of the study team. Two members of the study team attended all of the focus groups. One member of the team recorded the focus group discussions in field notes. The trained observer recorded participant interaction and intensity of discussions in the form of gesticulations, head nodding, and other nonverbal group participation.

\section{Development of moderator guide}

In accordance with the PHM framework, the focus group moderator guide questions sought to determine participants' salient beliefs and referents (e.g., salient beliefs about threat and response efficacy). A series of questions were posed to solicit information on all PHM framework constructs, including whether or not the target audience perceived that they were at risk of breast cancer, their thoughts about disease severity, whether there were actions they could take to ameliorate effect of the disease, and whether people close to them viewed breast cancer and screening as an important issue. The moderator guide also facilitated obtaining information about audience cues (e.g., cultural values, perceived barriers, healthrelated customs), and preferences for concepts and messages. Here we attempted to determine what message characteristics would contribute to an appealing message able to motivate women to get screened for breast cancer in addition to attributes perceived to be culturally relevant. Most importantly, we sought to identify potential barriers to screening that should be addressed in campaign messages created for this target audience. Table 1 presents a crosswalk of PHM constructs with key focus group questions. The table also includes selected responses to the moderator guide questions posed that were used to inform the development of persuasive messages and ad-like materials/concept boards.

\section{Data analysis}

The PDIS data were analyzed using SPSS version 10.0 (IBM, Chicago, IL). We used detailed field notes and audiotapes to analyze the focus group discussions; the audiotapes were transcribed and imported into ATLAS.ti 5.0 (ATLAS.ti Scientific Software Development Gmbh, Berlin Germany), a qualitative data analysis software program used to organize and manage text data for analysis.

Some themes identified from the analysis of field notes were articulated directly by participants. For others, we sought to identify patterns and themes that were clearly and frequently expressed within each group, as well as those that were more subtle or voiced less often. We also considered those ideas or thoughts that were nonverbally supported by group members, even if they were not repeated by others in the groups. 


\section{Results}

\section{Applying the PHM framework}

Step 1: Determining information about threat and efficacy

- Determine salient beliefs and salient referents

- Specify behavioral goal (recommended response)

- Determine barriers to self-efficacy and address in message

Using questions guided by the PHM, we determined perceived susceptibility, the likelihood that a threat will occur to a given person or audience, and severity, the magnitude of harm expected from a threat, in our target audience. Across groups, participants shared the belief that African American women in general were at increased risk of developing breast cancer due to family history of cancer, poor diet, and lack of health insurance. PDIS data revealed that screened women (50\%) more frequently reported being "very likely" to get breast cancer than unscreened women (30\%). Most participants (86\% of screened women, $92 \%$ of unscreened women) perceived breast cancer to be "very serious." Participants said that their initial thought about breast cancer was death, followed by fears about any pain involved with having a mammogram, the possibility of mastectomy, the physical pain of being sick, hair loss, loss of finances, inability to work or pay for treatment, and long-term treatment of the disease.

Participants' response- and self-efficacy, such as beliefs that early detection can mitigate the consequences of breast cancer and confidence in being able to obtain a mammogram, were also investigated. Data from the PDIS showed that across groups, half of the participants "strongly agreed" (screened women $53 \%$, unscreened women $50 \%$ ) that breast cancer screening will help keep them from dying of breast cancer. However, participants were generally unaware of national guidelines for getting a mammogram [19] and offered varied thoughts about when a woman should obtain a mammogram, including the following: if she detects a lump in her breast; when she turns 40 years; at 18 years of age; when she becomes sexually active; every 3-6 months; and twice a year. Screened women who had recently received a mammogram through their local program were more likely than unscreened women to exhibit awareness of local screening services; however, overall, participants did not know the name of their local breast and cervical cancer screening program. Additionally, some women indicated that they would rather learn about prevention of breast cancer than early detection.

Across groups, we learned that family and friends were salient referents for participants; however, screened women were more likely than unscreened women to report having a family member or friend (especially a mother or sister) who had a mammogram or had some type of cancer. Many participants recounted that relatives diagnosed with cancer had strongly encouraged them to get screened, while others reported that friends who had cancer impressed upon them the importance of getting mammograms. Conversely, unscreened women commonly reported having no close personal relationships with family or friends who were affected by breast cancer. 
Potential barriers to self-efficacy, anything that might inhibit one from carrying out a recommended response, included concerns about mammograms, including dangers of exposure to radiation during screening, discomfort of the test, pain, and embarrassment exposing their bodies. Unscreened women were extremely skeptical about the quality of low- or no-cost mammograms and were ambivalent about technician qualifications; correct interpretation of results; technicians' treatment of them because they are African American, poor, and uninsured; and follow-up care if they were diagnosed with breast cancer.

Step 2: Develop audience profile

- Assess audience cultural and environmental information to develop cues

- Identify channel, message, and source preferences

Our target audience was low-income African American women of screening age for the NBCCEDP (40-64 years) in urban and suburban settings. Focus groups revealed information about culture and environment critical to understand this audience; namely, the fact that this cultural group does not commonly discuss cancer or their bodies with others, may be self-conscious and insecure about their bodies and breast size when getting a mammogram, and beliefs that the African American cultural diet (including drug and alcohol consumption), socioeconomic status, lack of insurance, and emotional stress contribute to a higher cancer mortality among African Americans. In addition, participants commonly reported their belief that African Americans do not receive adequate medical treatment for cancer because of lack of insurance, treatment costs, and unequal treatment by medical providers. Specifically related to the environment, participants said that low-income women often live near power lines that are perceived to increase cancer risk. These findings show important issues to consider in developing messages to persuade African American women to get mammograms.

We were able to ascertain channel, message, and source preferences from focus group participants. Participants commonly identified the health department, hospitals, churches, breast cancer survivors, doctors, and healthcare professionals as trusted organizations and sources to provide health information to African American women. Participants preferred survivors as trusted sources compared to celebrities as they felt celebrities may be paid for their services, making their messages suspect. Survivors were perceived to not have anything to sell and were perceived as altruistic when sharing their stories.

In terms of channels, participants preferred to receive health information via print media in the mail, at doctor's offices, and from the health department; however, they were also receptive to receiving health information via the radio. In fact, data from the PDIS showed that $55 \%$ of participants reported listening to radio daily and $75 \%$ listened three or more times per week for Gospel (25\%), Christian (16\%), and R\&B (13\%) formats. Regarding message type and tone, across groups, participants stated that they wanted factual, serious health messages about breast cancer and mammography disseminated to them via print media, radio, and television. Participants reported that serious messages showing concern, sympathy, and reassurance; messages providing statistics about breast cancer risk among African American women specifically; and messages stating how early detection can save 
lives would be the most effective in motivating African American women to get screened for breast cancer.

At the end of each focus group, participants were asked to suggest a health message to reach and motivate a lot of women like them to get a mammogram. Participants' messages stressed the importance of mammograms for early detection and discussed how early detection can increase women's chances of surviving breast cancer. Most participants' messages were short phrases meant to catch women's attention and included phrases such as early detection "saves lives." Participants also used terms such as "better safe than sorry" to refer to the need for early diagnosis of breast cancer and stressed the importance of remaining "educated" about one's own health.

Step 3: Construct persuasive message

- Create messages that fit with the audience and their salient beliefs and referents

- Try to reinforce existing beliefs, change beliefs, or introduce new beliefs

- Test draft messages with target audience, and modify as needed

As shown in Table 2, the information gathered from focus groups was used to construct persuasive messages presented in draft concept boards (Fig. 1) to promote the availability of local mammography screening services to low-income African American women aged 4064 years. As per target audience suggestions, the messages indicated how breast cancer can affect anyone regardless of age, gender, or race. Based on data gathered in PHM steps 1 and 2, persuasive messages were created to emphasize that African American women are at risk and susceptible to the threat of breast cancer and that their personal action to obtain regular mammograms may lead to early detection, subsequent treatment, and reduced cancer mortality. In addition, the messages addressed concerns of self-efficacy by emphasizing that uninsured women can obtain low- or no-cost mammograms locally and that no-cost screening services are of high quality and use the same equipment/staff used by paying patients. To address concerns about whether mammograms can detect cancer (response efficacy), the messages reinforced the facts that breast cancer screening leads to early detection, that it saves lives, and that, although mammograms may be uncomfortable, they are key to finding cancer early. In an attempt to combat the sentiment that breast cancer is a death sentence, the messages indicated that breast cancer can be successfully treated, especially when detected early. Furthermore, persuasive arguments were created to correct inaccurate perceptions of appropriate screening age and frequency.

Based on participant responses, we ensured that elements of the messages (non-content aspects of the message) fit the target audience cultural values and source/channel preferences. For example, African American breast cancer survivor testimonials were used as the message centerpiece, flanked by an opening statement identifying that the message was from CDC (a trusted source) and a closing statement from a physician stating the benefit of early detection and assuring quality of free services. All visual and audio message elements included a call to action to call 1-800-4CANCER to obtain a low- or no-cost mammogram. The testimonials of breast cancer survivors-identified as key messengersserved as the cornerstone of the radio spots and sought to address women's fear of 
diagnosis, concerns about family history, concerns about test discomfort, and emphasized the benefit of women being proactive about their health to get mam-mograms for early detection.

Per the final PHM framework guidance step, draft campaign messages (Fig. 1) were evaluated by members of the target audience (in an additional eight focus groups) to ensure that the messages (and materials) could produce our health communication goals. This second round of focus groups was convened in 2007 to test audience response to draft audio messages and print messages in concept boards. Most notably, in addition to suggestions made to wording, participants expressed distinct preferences for images relative to skin color, hairstyle, and body size. The findings of message/materials testing resulted in a number of refinements to specific wording and images made in accordance with audience feedback received [18].

\section{Discussion}

The PHM framework helped facilitate the development of culturally appropriate messages and images that reflected the sensitivities and preferences of a segment of our target audience for a multi-component mass media campaign to promote breast cancer awareness and mammography screening among low-income African American women in Macon and Savannah, GA, using two rounds of focus group testing to gather data from our target audience. The use of the PHM framework, composed of many theories, facilitated our understanding of the factors that influenced target audience behaviors and better positioned us to devise strategies and methods to achieve our goals to motivate low-income African American women to get mammograms. A great value of using the PHM framework is that it guided understanding of audience beliefs (specifically how and why African American women think about health and cancer), behaviors (specifically how and why African American women do or do not get mammograms), and informed how to create and target persuasive campaign messages to address those beliefs and address any barriers to getting screened. Following framework guidance enabled identification of pathways to influence and motivate behaviors and identification of viable communication strategies to encourage or change African American women's behaviors to obtain mammograms.

Second, the use of the PHM framework proved to be valuable in guiding our efforts to develop a culturally appropriate intervention attentive to "deep structure" components. As noted by Freimuth and Quinn [20], several health communication efforts address what is known as the "surface structure" of a culture. Addressing "surface structure" involves matching public health communication/campaign messages and channels to observable social and behavioral characteristics of a culture, such as to people's food, familiar people, and language. However, it is critically important to address "deep structure" issues, which reflect the cultural, social, psychological, environmental, and historical factors that impact a vulnerable or minority community [21]. The constructs in the PHM framework (see Table 1) require attention to "deep structure" constant and transient components such as perceived threat and salient beliefs, salient references, culture, and environment, which led to examination of "deep structure" issues such as African American's mistrust of the medical establishment due to historical injustices, concerns about the quality of free services, 
perception of mammograms as dangerous, and limited discussion of disease and private parts (e.g., breasts) in African American communities.

There are several advantages in using theory to develop materials to target specific audiences. Prior studies have shown that theoretically based persuasive messages result in greater levels of health-protective behaviors, are more efficient, and often are cheaper to develop [22]. Furthermore, research has shown that theoretically guided campaign messages have a greater chance for success, achieve their goals in a more efficient and timely manner, and cost less to conduct. The trial-and-error process used to develop a theory in both laboratory and field research means that practitioners do not have to guess about what works and what does not. In short, theories, models, and frameworks communicate which beliefs to address in a communication campaign (which are stronger or weaker), and the types of persuasive arguments or messages that are most likely to lead to desired health beliefs and health protection behaviors. To this end, the development of messages and materials for the AAMM pilot campaign benefitted from the use of the PHM framework to facilitate identification of low-income African American women's salient beliefs about breast cancer and mammography screening to reinforce, introduce, and change in order to promote utilization of NBCCEDP breast cancer screening services.

Conversely, there are expressed limitations to using theory or a theory-based framework, such as the PHM framework. Some may argue that the PHM framework may be too stepdriven, inflexible, and even simplistic in how it directs practitioners to collect constant and transient data to create persuasive campaign messages. However, we found the framework, which includes environment as a key construct, worthy of investigation to assist creation of campaign messages to motivate behavior change. An additional limitation of our findings is that these data were obtained nearly a decade ago, and there is the possibility that what lowincome African American women perceive as culturally sensitive and appropriate has changed since that time. Through conduct of recent research to update our work and ensure relevance to a similar audience in a different setting, we identified temporal changes in audience receptivity to images, such as women's openness and positive response to natural hair and darker skin color, and preference for even more directive health messages to promote mammography. We also learned of differences in audience demographics whereby more contemporary audiences meeting eligibility for the NBCCEDP were more likely to have higher education and be transiently unemployed, reflecting recent downturns in the economy since our first effort. However, the fundamental PHM framework tenets of addressing threat and self-efficacy, perceived barriers to efficacy, and identifying appropriate message channels remained constant.

In conclusion, using the PHM framework helped eliminate some of the pitfalls associated with formation of poor health communication messages, such as inattention to constructs such as culture and environment that influence people's beliefs, perceptions, and behaviors. The use of the PHM framework made clear our selection and investigation of constructs necessary to create and justify choices to create persuasive communication messages for the AAMM pilot campaign. In a public health environment that increasingly places greater emphasis on cost-effectiveness alongside the move to evidence-based practice, it seems critical to use theory or frameworks to help ensure the development of effective 
communication campaigns $[1,23]$. The PHM framework offered an easy-to-follow, flexible multi-step process that facilitated creation of a persuasive pilot campaign contributing to increased awareness and mammography screening among low-income African American women in Georgia.

\section{References}

1. Jones S, Donovan R. Does theory inform practice in health promotion in Australia? Health Educ Res. 2004; 19:1-14. [PubMed: 15020541]

2. Corcoran, N. Communicating health: strategies for health promotion. Thousand Oaks: Sage Publications; 2007.

3. Tones, K.; Tilford, S. Health education effectiveness, efficiency and equity. 2nd. London: Chapman \& Hall; 1994.

4. Trifletti LB, Gielen AC, Sleet DA, Hopkins K. Behavioral and social science theories and models: are they used in unintentional injury prevention research? Health Educ Res. 2005; 20:298-307. [PubMed: 15632096]

5. Parker EA, Baldwin GT, Israel B, Salinas M. Application of health communication theories and models for environmental health. Health Educ and Behav. 2004; 31:491-509.

6. Fishbein M, Ajzen I. Belief, attitude, intention and behavior: an introduction to theory and research. Addison-Wesley, Reading. 1975

7. Petty, RE.; Cacioppo, JT. Communication and persuasion: central and peripheral routes to attitude change. New York: Springer; 1986.

8. Rogers, RW. Cognitive and physiological processes in fear appeals and attitude hange: a revised theory of protection motivation. Caccioppo, J.; Petty, R., editors. Guilford, New York: Social psychophysiology; 1983. p. 153-176.

9. Witte, K. Fishing for success using the persuasive health message framework to generate effective campaign messages. In: Maibach, EW.; Parrott, RL., editors. Designing health messages: approaches from communication theory and public health practice. Thousand Oaks: Sage Publications; 1994.

10. Witte K, Peterson TR, Vallabhan S, Stephenson MT, Plugge CD, Givens VK, Todd JD, Becktold MG, Hyde MK, Jarrett R. Preventing tractor-related injuries and deaths in rural populations: using a persuasive health message framework in formative evaluation research. Int Q Community Health Educ. 1992; 13:219-251. [PubMed: 20840987]

11. Tan-Wilhelm D, Witte K, Liu W-Y, Newman LS, Janssen A, Ellison C, Yancey A, Wayne Sanderson W, Henneberge PK. Impact of a worker notification program: assessment of attitudinal and behavioral outcomes. Am J Ind Med. 2000; 37:205-213. [PubMed: 10615101]

12. Carcioppolo N, Jensen JD, Wilson SR, Collins WB, Carrion M, Linnemeier G. Examining HPV threat-to-efficacy ratios in the Extended Parallel Process Model. Health Commun. 2013; 28:20-28. [PubMed: 23330855]

13. Duong J, Bradshaw CP. Using the extended parallel process model to examine teachers' likelihood of intervening in bullying. J Sch Health. 2013; 83:422-429. [PubMed: 23586887]

14. Lewis I, Watson B, White KM. Extending the explanatory utility of the EPPM beyond fear-based persuasion. Health Commun. 2013; 28:84-98. [PubMed: 23330861]

15. Hall IJ, Rim SH, Johnson-Turbes CA, Vanderpool R, Kamalu NN. The African American women and mass media campaign: a CDC breast cancer screening project. J Women's Health. 2012; 21:1107-1113.

16. Hall IJ, Johnson-Turbes CA, Berkowitz A, Zavahir Y. The African American Women and Mass Media (AAMM) Campaign in Georgia: quantifying community response to a CDC pilot campaign. Canc Causes Control. 2014

17. Witte K. Theory-based interventions and evaluations of outreach efforts. National Network of Libraries of Medicine. 2007 http://nnlm.gov/evaluation/pub/witte/. 
18. Leeks KD, Hall IJ, Johnson-Turbes CA, Kamalu NK, Zavahir Y. Formative development of a culturally appropriate mammography screening campaign for low-income African-American women. J Health Dispar Res Pract. 2012; 5:42-61.

19. U.S. Preventive Services Task Force: Recommendations and Rationale Screening for breast cancer: recommendations and rationale. Am Fam Physician. 2002; 65:2537-2545. [PubMed: 12086243]

20. Freimuth V, Quinn SC. The contributions of health communication to eliminating health disparities. Am J Public Health. 2004; 94:2053-2055. [PubMed: 15569949]

21. Resnicow K, Baranowski T, Ahluwalia JS, Braithwaite RL. Cultural sensitivity in public health: defined and demystified. Ethn Dis. 1999; 9:10-21. [PubMed: 10355471]

22. Maibach, E.; Parrot, R. Designing health messages: approaches from communication theory and public health practice. Thousand Oaks: Sage Publications; 1995.

23. Koebetz E, Vataloro K, Moore A, Earp JA. Taking the transtheoretical model to the field: a curriculum for lay health advisors. Health Promot Pract. 2005; 6:329-337. [PubMed: 16020627] 

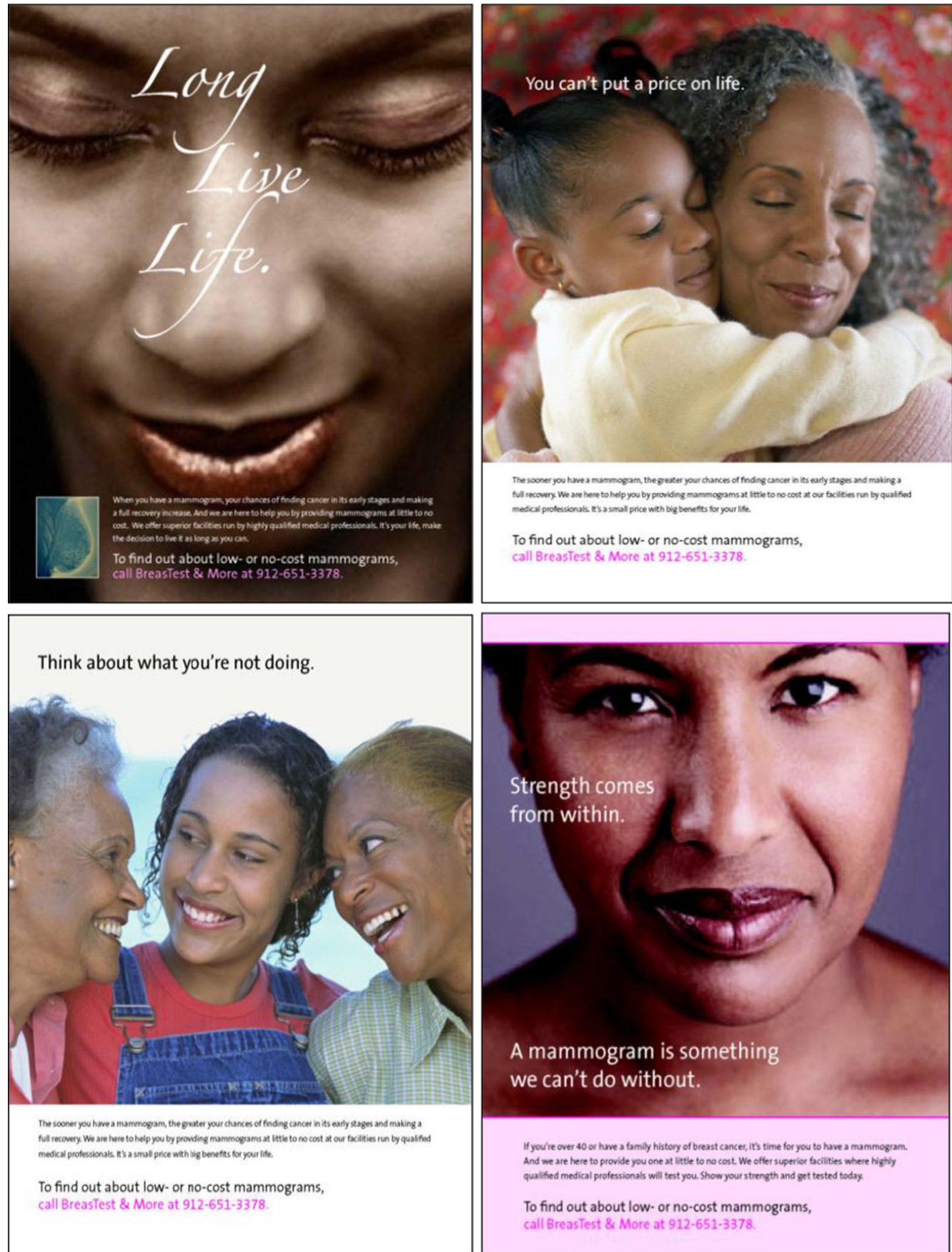

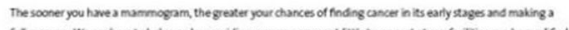

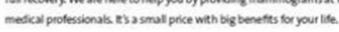

To find out about low- or no-cost mammograms, call BreasTest \& More at 912-651-3378.

Fig.1.

Draft messages in concept boards

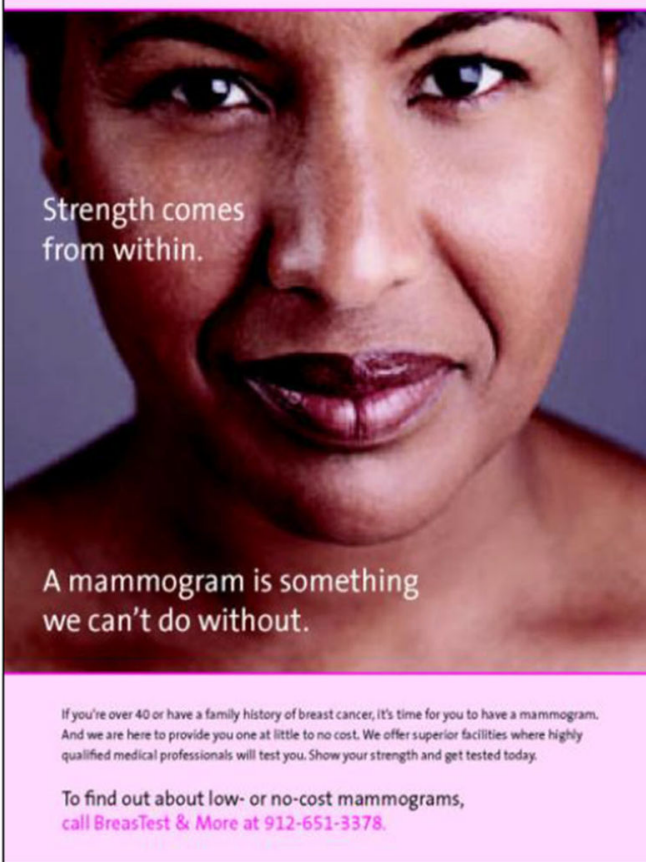

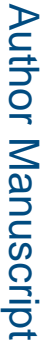

Cancer Causes Control. Author manuscript; available in PMC 2016 May 01. 
Table 1

Crosswalk of PHM constructs, corresponding formative research questions ${ }^{a}$, and selected participant responses

\begin{tabular}{|c|c|c|}
\hline $\begin{array}{l}\text { PHM framework } \\
\text { construct }\end{array}$ & Formative evaluation questions linked to the PHM & Summary of formative evaluation findings \\
\hline \multicolumn{3}{|l|}{ Constant } \\
\hline \multirow{5}{*}{$\begin{array}{l}\text { Threat } \\
\text { (susceptibility, } \\
\text { severity) }\end{array}$} & What comes to your mind when I say "breast cancer?" & African American women are at risk of breast cancer \\
\hline & $\begin{array}{l}\text { Do you think women like you are at risk for getting } \\
\text { breast } \\
\text { cancer? }\end{array}$ & $\begin{array}{l}\text { African American women are more likely than white women } \\
\text { to die from breast cancer }\end{array}$ \\
\hline & & $\begin{array}{l}\text { There was a general sense of fear about breast cancer } \\
\text { Breast cancer means death }\end{array}$ \\
\hline & & $\begin{array}{l}\text { Diabetes, HIV, and hypertension are of greater concern in the } \\
\text { African American community }\end{array}$ \\
\hline & & $\begin{array}{l}\text { Participants believe that (1) breast cancer is hereditary, ( } 2) \\
\text { diet influences cancer risk, and ( } 3 \text { ) environment influences } \\
\text { risk }\end{array}$ \\
\hline \multirow[t]{4}{*}{$\begin{array}{l}\text { Efficacy (self, } \\
\text { response) }\end{array}$} & $\begin{array}{l}\text { What can women do protect themselves from getting } \\
\text { breast } \\
\text { cancer? (self-efficacy) }\end{array}$ & $\begin{array}{l}\text { Mammograms and self-exams help early detection of breast } \\
\text { cancer }\end{array}$ \\
\hline & $\begin{array}{l}\text { Do you think that breast cancer screening increases the } \\
\text { chance of finding breast cancer early? (response efficacy) }\end{array}$ & $\begin{array}{l}\text { Early detection increases the chance for survival of breast } \\
\text { cancer }\end{array}$ \\
\hline & $\begin{array}{l}\text { Do you think that breast cancer screening increases a } \\
\text { woman's chance of surviving breast cancer? }\end{array}$ & $\begin{array}{l}\text { Women should get mammograms starting in their } \\
\text { childbearing years }\end{array}$ \\
\hline & & Women should get mammograms more than once per year \\
\hline \multirow[t]{8}{*}{$\begin{array}{l}\text { Cues } \\
\text { (channel, } \\
\text { source) })^{b}\end{array}$} & $\begin{array}{l}\text { Where do you usually get your information about } \\
\text { "general } \\
\text { health?" }\end{array}$ & $\begin{array}{l}\text { Pamphlets (received via mail or obtained in a doctor's office, } \\
\text { health department, local pharmacies, grocery, or at church) } \\
\text { are the preferred way to received information about breast }\end{array}$ \\
\hline & $\begin{array}{l}\text { What would you want to know about the screening } \\
\text { services } \\
\text { in your area? }\end{array}$ & cancer an mammograms \\
\hline & $\begin{array}{l}\text { How would you want to receive information about breast } \\
\text { cancer screening? }\end{array}$ & $\begin{array}{l}\text { Participants were open to receiving information via radio or } \\
\text { television }\end{array}$ \\
\hline & $\begin{array}{l}\text { Who would you want to hear the message from? Who } \\
\text { would } \\
\text { you most believe? }\end{array}$ & $\begin{array}{l}\text { If radio is used to share information, then air ads on Gospel } \\
\text { stations }\end{array}$ \\
\hline & $\begin{array}{l}\text { What types of messages would improve the chances that } \\
\text { you } \\
\text { would pay attention? }\end{array}$ & $\begin{array}{l}\text { African American women would be more likely to get } \\
\text { mammograms if it was widely known that free } \\
\text { mammograms are available }\end{array}$ \\
\hline & & $\begin{array}{l}\text { Testimonials and information about breast cancer from other } \\
\text { women (particularly survivors) would be most effective to } \\
\text { promote mammography among women }\end{array}$ \\
\hline & & $\begin{array}{l}\text { Messages should include factual information and reinforce } \\
\text { how early detection, be pleasant, firm, direct, and serious }\end{array}$ \\
\hline & & $\begin{array}{l}\text { Messages should promote hope and possibility of survival; } \\
\text { should be easy to understand, not use humor or fear tactics }\end{array}$ \\
\hline
\end{tabular}

Transient

Salient beliefs
Do you think that women like you are at risk for getting breast cancer?

How would you find out if you had breast cancer?
African American women are at risk of breast cancer Almost all participants reported that a mammogram was the best way to find out if they had breast cancer

Some screened participants also discussed self-exams and clinical breast exams as effective ways to detect a breast lump and possibly breast cancer

Unscreened participants did not commonly mention self or clinical breast exams as a way to find out if they had cancer 


\begin{tabular}{|c|c|c|}
\hline $\begin{array}{l}\text { PHM framework } \\
\text { construct }\end{array}$ & Formative evaluation questions linked to the PHM & Summary of formative evaluation findings \\
\hline \multirow[t]{2}{*}{ Salient referents } & $\begin{array}{l}\text { [If screened] What influenced (or motivated) you to get } \\
\text { screened for breast cancer in the past eighteen months? } \\
\text { Did } \\
\text { a friend (or friends) encourage you to get screened? } \\
\text { [If unscreened] Has any of your family or friends been } \\
\text { screened for breast cancer? Do they encourage you to get } \\
\text { screened for breast cancer? }\end{array}$ & $\begin{array}{l}\text { For screened women, family and friends motivated } \\
\text { participants to get a mammogram } \\
\text { For unscreened women, family and friends did not motivate } \\
\text { participants to get mammograms }\end{array}$ \\
\hline & $\begin{array}{l}\text { Do your family/friends think that screening for breast } \\
\text { cancer } \\
\text { increases a woman's chances of surviving breast cancer? }\end{array}$ & \\
\hline \multirow[t]{5}{*}{$\begin{array}{l}\text { Culture and } \\
\text { environment }\end{array}$} & $\begin{array}{l}\text { What do you think should be the main point of health } \\
\text { messages to promote breast cancer screening among } \\
\text { African American women? }\end{array}$ & $\begin{array}{l}\text { Women are most likely to listen to messages about breast } \\
\text { cancer when they are at the doctor, church, grocery stores, } \\
\text { and hair salons }\end{array}$ \\
\hline & $\begin{array}{l}\text { Are there times or places where you pay better attention } \\
\text { to } \\
\text { health messages? }\end{array}$ & $\begin{array}{l}\text { Some participants expressed concern about the quality and } \\
\text { accuracy of free mammograms and the timeliness of results }\end{array}$ \\
\hline & $\begin{array}{l}\text { What are your thoughts about free or low-cost breast } \\
\text { cancer } \\
\text { screening? }\end{array}$ & $\begin{array}{l}\text { Some women were open to and receptive to free } \\
\text { mammograms and had no doubts about quality of services }\end{array}$ \\
\hline & $\begin{array}{l}\text { Why do you think that some women choose not to get } \\
\text { screened for breast cancer? }\end{array}$ & $\begin{array}{l}\text { Women who do not get mammograms (1) do not know about } \\
\text { free services, (2) are afraid that mammograms are painful } \\
\text { and uncomfortable, and ( } 3 \text { ) are afraid of finding out if they } \\
\text { have cancer, and (4) are concerned about the healthcare } \\
\text { costs of treating cancer }\end{array}$ \\
\hline & & Breast cancer is not often discussed; it is a taboo subject \\
\hline
\end{tabular}

${ }^{a}$ The moderator guide questions presented here do not represent all of the focus group questions asked or represent the only questions that can be linked to the PHM. These questions are presented as some of the key questions asked of focus group participants in order to obtain information on PHM constructs to develop the AAMM campaign concepts, messages, and materials tested for this study

\section{${ }^{b}$}

A source is who/what delivers or transmits a message or information. The source influences the credibility and effectiveness of a message for a target audience. The channel is the means by which a message is sent. Channel selection is as important as message selection, and using multiple channels (e.g., radio and print) to communicate information is an effective strategy to reach a target audience 


\section{Table 2}

\section{Draft message components}

\begin{tabular}{llll}
\hline Beliefs to reinforce & Beliefs to introduce & Beliefs to change & Audience profile \\
\hline $\begin{array}{l}\text { African American women are } \\
\text { at risk of breast cancer }\end{array}$ & $\begin{array}{l}\text { Low- or no-cost mammograms are } \\
\text { available locally }\end{array}$ & $\begin{array}{l}\text { Breast cancer is a death } \\
\text { sentence }\end{array}$ & $\begin{array}{l}\text { African American women } \\
\text { Aged 40-64 years }\end{array}$ \\
$\begin{array}{lll}\text { Early detection saves lives } \\
\text { Mammography services can be obtained } \\
\text { even if uninsured }\end{array}$ & $\begin{array}{l}\text { Free services are of inferior } \\
\text { quality }\end{array}$ & Urban \\
$\begin{array}{l}\text { Breast cancer can be treated } \\
\text { successfully }\end{array}$ & $\begin{array}{l}\text { Free services are conducted with same } \\
\text { equipment/staff of paying patients }\end{array}$ & $\begin{array}{l}\text { Women should get multiple } \\
\text { mammograms each year }\end{array}$ & $\begin{array}{l}\text { Radio listeners: gospel, R\&B } \\
\text { Use survivor testimonials } \\
\text { uncomfortable }\end{array}$ \\
\hline
\end{tabular}

